Abstract

\title{
Design and Synthesis of Cysteine Protease Inhibitors ${ }^{\dagger}$
}

\section{Florenci V. Gonzalez}

Department de Química Inorgànica i Orgànica, Universitat Jaume I, 12071 Castelló, Spain; fgonzale@uji.es † Presented at the 1st Molecules Medicinal Chemistry Symposium, Barcelona, Spain, 8 September 2017.

Published: 18 October 2017

We have been preparing new dipeptidyl inhibitors against parasitic cysteine proteases cruzain (related to Chagas disease) and rhodesain (related to Sleeping Sickness disease), and against human cathepsins. Inhibitors display new warheads embedded into a dipeptidic framework. Dipeptidyl epoxyesters [1] and Dipeptidyl enoates [2] are highly potent irreversible inhibitors of cruzain and rhodesain. We also prepared an oxidized version of well-known Vinylsulfones (Epoxysulfones [3]) as inhibitors of human cathepsins. Recently, we have reported the synthesis of Dipeptidyl nitroalkenes [4] as a new type of highly potent covalent reversible inhibitors of cysteine proteases exhibiting certain selectivity for the parasitic cysteine proteases rhodesain and cruzain.

Acknowledgments: The author thanks Generalitat Valenciana (AICO/2016/32) for financial support.

Conflicts of Interest: The author declares no conflicts of interest.

\section{References}

1. González, F.V.; Izquierdo, J.; Rodríguez, S.; McKerrow, J.H.; Hansell, E. Dipeptidyl $\alpha, \beta$-Epoxyesters as Potent Irreversible Inhibitors of the Cysteine Proteases Rhodesain and Cruzain. Bioorg. Med. Chem. Lett. 2007, 17, 6697-6700.

2. Royo, S.; Rodríguez, S.; Schirmeister, T.; Kesselring, J.; Kaiser, M.; González, F.V. Dipeptidyl Enoates as Potent Rhodesain Inhibitors that display a Dual Mode of Action. Chem. Med. Chem. 2015, 10, 1484-1487.

3. Latorre, A.; Rodríguez, S.; González, F.V.; Florea, B.I.; Overkleeft, H.S. Synthetic Studies on the Preparation of Alanyl Epoxysulfones as Cathepsin Cysteine Protease Electrophilic Traps. J. Org. Chem. 2015, 80, 7752-7756.

4. Latorre, A.; Schirmeister, T.; Kesselring, J.; Jung, S.; Johé, P.; Hellmich, U.A.; Heilos, A.; Engels, B.; Krauth-Siegel, R.L.; Dirdjaja, N.; et al. Dipeptidyl Nitroalkenes as Potent Reversible Inhibitors of Cysteine Proteases Rhodesain and Cruzain. ACS Chem. Med. Lett. 2016, 12, 1073-1076.

(C) 2017 by the authors. Licensee MDPI, Basel, Switzerland. This article is an open access article distributed under the terms and conditions of the Creative Commons Attribution (CC BY) license (http://creativecommons.org/licenses/by/4.0/). 